\title{
Improved geoid model determination for Japan from GRACE and a regional gravity field model
}

\author{
Yuki Kuroishi \\ Geographical Survey Institute, 1 Kitasato, Tsukuba, Ibaraki 305-0811, Japan
}

(Received July 17, 2008; Revised November 21, 2008; Accepted January 6, 2009; Online published August 31, 2009)

\begin{abstract}
A highly improved gravimetric geoid model for Japan, JGEOID2008, is developed on a $1 \times 1.5$ arc-minute grid by combining a GRACE (the Gravity Recovery And Climate Experiment)-based global geopotential model, GGM02C, surface (land and ship-borne) gravity measurements, and an altimetry-derived marine gravity model, KMS2002. In the combination, a semidiscrete two-dimensional wavelet analysis/reconstruction method is employed, selecting the spatial wavelength signals of the highest quality out of the respective data sets. Intercomparison with GPS/leveling geoid undulations shows substantial improvement of JGEOID2008 over the previous model, JGEOID2004, and reveals that the systematic errors at long wavelengths contained in JGEOID2004 have been effectively removed. Deviations of JGEOID2008 from the mean sea surface height at tidal stations on isolated islands were comparable to the differences in the sea surface dynamic heights (SSDH) in the Japan Sea, the Nansei Islands and the Izu Island chain from that in Tokyo Bay. The deviations show good agreement with SSDH features estimated from oceanographic observation, indicating that JGEOID2008 has an accuracy within $10 \mathrm{~cm}$. The geoid model is strongly expected to serve as a reference in ocean dynamics studies.
\end{abstract}

Key words: Local geoid, gravity, GRACE, combination, wavelet, sea surface dynamic height.

\section{Introduction}

The success of the dedicated satellite gravity missions, such as the Gravity Recovery And Climate Experiment (GRACE), to directly observe the Earth's gravity field and its temporal changes on a global scale has been yielding breakthroughs in multidisciplinary studies of geodynamics. The time-variable gravity field observed captures the temporal mass transport on a large scale occurring in the atmosphere and the hydrosphere of the Earth's system (e.g., Tapley et al., 2004; Wahr et al., 2004). In addition, the static gravity field is also determined with unprecedented accuracy at long wavelengths.

The long-term prediction of climate change, on the other hand, is a common challenge to humans, which requires the clarification of the general global circulation mechanism of the atmosphere and the ocean interacting with each other. For that purpose we need to fully understand ocean dynamics, although detailed three-dimensional observation over the whole ocean is impractical. Consecutive missions of satellite altimetry have enabled the observation of sea surface height (SSH) changes precisely and globally in a geometrical sense, and now we must understand the currents, mixing, and thermal exchanges at depth in the ocean. Geometric changes of the observed SSH involve a steric part (i.e., density changes associated with the variations in the temperature and salinity of the water column) as well as a dynamic part, and therefore, we should distinguish the former from the latter to enhance the study of ocean dynamics.

Copyright (c) The Society of Geomagnetism and Earth, Planetary and Space Sciences (SGEPSS); The Seismological Society of Japan; The Volcanological Society of Japan; The Geodetic Society of Japan; The Japanese Society for Planetary Sciences; TERRAPUB.
Since the fundamental information on ocean dynamics is the sea surface dynamic topography (SSDT) in an absolute sense, oceanographers request geodesists to determine the geoid over the ocean as a reference surface within the accuracy of, for example, $10 \mathrm{~cm}$.

Japan and its surroundings are one of the most challenging regions in studies of geoid determination and of oceanography. The area is located at the convergence boundaries of four tectonic plates and the existence of deep trenches and subducting oceanic plates produces very complicated variations in the gravity field and in the geoid geometry. Moreover, the pertinent area of the Pacific Ocean is very dynamic: the Kuroshio Current flows south of Japan, releasing a huge amount of heat from the ocean to the atmosphere, and the Shichito-Iojima ridge blocks and disturbs (deep) ocean currents.

Regional gravimetric modeling for the area around Japan has been studied by Kuroishi (1995, 2001a, b) and Kuroishi and Keller (2005) in order to determine the geoid with improved accuracy over the land. The latest model, JGEOID2004 (Kuroishi and Keller, 2005), contains some systematic errors at long wavelengths, presumably attributed to errors in its foundational global geopotential model (GGM). JGEOID2004 is developed by combining terrestrial gravity data (land and ship-borne measurements) and an altimetric global marine gravity anomaly model, KMS2002 (Andersen et al., 2005) with a GGM, EGM96 (Lemoine et al., 1997), as the foundational model. EGM96 was determined prior to the advent of dedicated gravity satellite missions and may suffer from systematic errors at long wavelengths.

In this study, we try to determine the geoid for Japan 
(a)

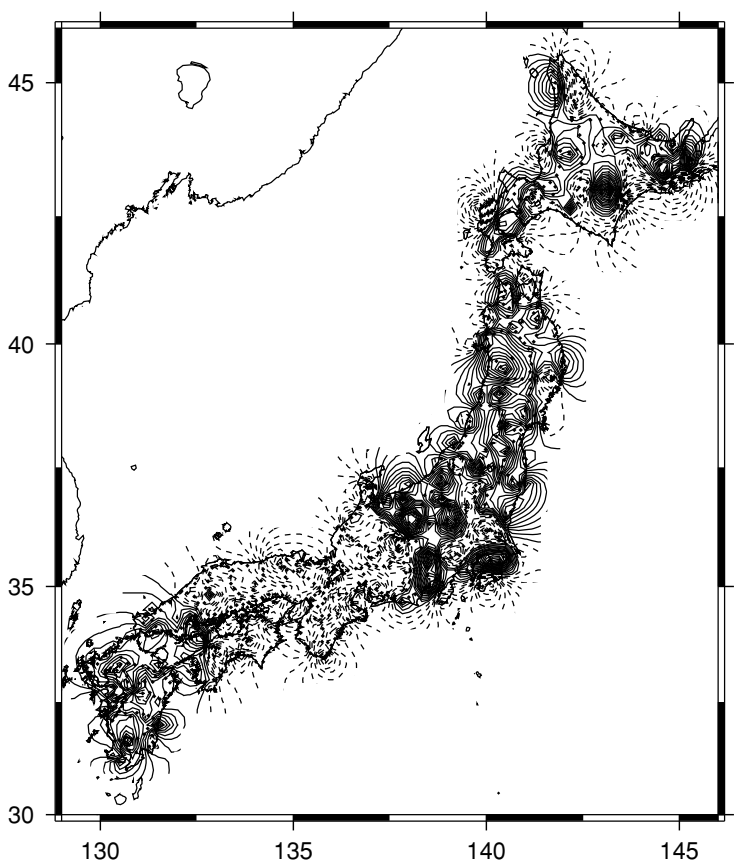

(b)

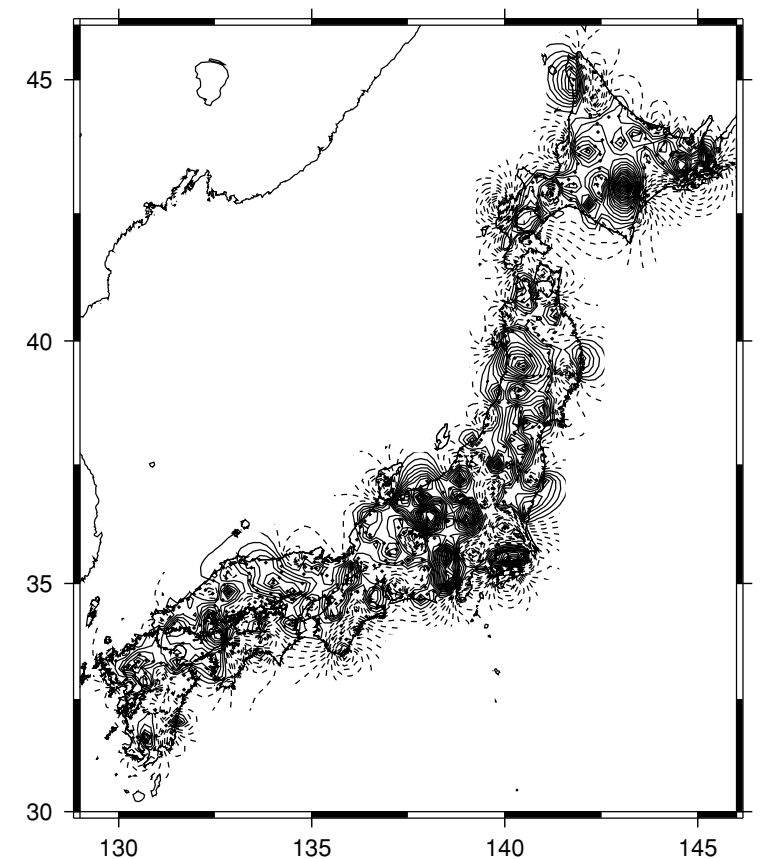

Fig. 1. Geoid differences between GGMs and GPS/leveling geoid undulations: (a) EGM96 and (b) GGM02C/EGM96. Best-fit planar trends are removed from both plots. Dots show the locations of GPS at benchmarks. Contour intervals are $5 \mathrm{~cm}$ and broken lines correspond to negative values. Values are in meters.

Table 1. Planar fitting of GGM geoid models to GPS/leveling geoid undulations at 816 benchmarks and statistics of direct geoid differences and their postfit residuals for EGM96 (complete to degree and order 360) and GGM02C/EGM96 (GGM02C complete to degree and order 200, merged with EGM96 from degrees 201 to 360). SD stands for standard deviation about the mean or the fitted plane.

\begin{tabular}{l|cc|ccc}
\hline \multirow{2}{*}{ GGM } & \multicolumn{2}{|c|}{ Direct differences } & \multicolumn{3}{c}{ Planar fit } \\
\cline { 2 - 6 } & Mean $(\mathrm{cm})$ & SD $(\mathrm{cm})$ & Tilt $(\mathrm{ppm})$ & Azimuth $\left(^{\circ}\right)$ & SD $(\mathrm{cm})$ \\
\hline EGM96 & -30.21 & 36.65 & 0.63 & 334 & 33.21 \\
GGM02C/EGM96 & -15.34 & 31.20 & 0.36 & 109 & 29.93 \\
\hline
\end{tabular}

at an accuracy of $10 \mathrm{~cm}$ or better by using a GRACEbased GGM. The resulting geoid model is evaluated with GPS/leveling geoidal undulation data over Japan. Since the leveled heights on isolated islands refer to the local mean sea level, the deviations of the geoid model from GPS/leveling data indicate the differences in SSDT between the main and the isolated islands. The geoid model is also compared and discussed with an oceanographically determined SSDT model.

\section{Geoid Undulation Performance of Global Geopotential Models over Japan}

The geoid can be determined regionally from regionally detailed and precise information on the gravity field with reference to a relevant GGM. The accuracy of such a regional geoid model at long wavelengths is governed by that of the GGM. Thus, we first evaluate, over Japan, the accuracy of some GGMs, namely, EGM96 and a GRACE-based combined GGM, GGM02C (Tapley et al., 2005).

In the evaluation we use geoid undulations obtained in the nationwide net of GPS at 816 benchmarks (Kuroishi et al., 2002). Three-dimensional positions are determined from GPS observation in the ITRF94/GRS80 reference frame at epoch 1997.0 and Helmert orthometric heights are computed from leveling. Regarding permanent tidal deformation, the former is given in the tide-free system. On the other hand, no astronomical correction is applied in the latter. In order to improve the consistency between GPS and leveling data handling in terms of the permanent tide system, we apply correction to the leveled heights based on Ekman (1989), under the assumption that the leveled heights are given in the mean-tide system. The height correction values range up to \pm several centimeters for the area. The GPS/leveling geoid undulations thus processed are given in the tide-free system and used hereafter.

The differences between GGMs and GPS/leveling data are shown in Fig. 1 after the removal of best-fit planar trends (Table 1). GGM geoid heights are computed from EGM96 (complete to degree and order 360 in full), and from GGM02C (complete to degree and order 200) appended with EGM96 from degrees 201 to 360 (hereinafter called GGM02C/EGM96). In both cases, GRS80 (Moritz, 1980) is used as the reference ellipsoid, and the geocentric gravitational constant and geoidal potential taken from IERS Conventions 2003 (McCarthy, 2003) are employed for GGMs. The differences in the defining constants between GRS80 and GGMs are taken into account on the basis of Smith and Milbert (1999), and geoid heights are ex- 
Table 2. Planar fitting of gravimetric geoid models to GPS/leveling geoid undulations at 816 benchmarks over the four main islands of Japan and statistics of direct geoid differences and their postfit residuals. SD stands for standard deviation about the mean or the fitted plane.

\begin{tabular}{l|cc|ccc}
\hline \multirow{2}{*}{ Geoid model } & \multicolumn{2}{|c|}{ Direct differences } & \multicolumn{3}{c}{ Planar fit } \\
\cline { 2 - 6 } & Mean $(\mathrm{cm})$ & SD $(\mathrm{cm})$ & Tilt $(\mathrm{ppm})$ & Azimuth $\left(^{\circ}\right)$ & SD $(\mathrm{cm})$ \\
\hline JGEOID2004 & 50.42 & 11.03 & 0.35 & 142 & 9.22 \\
EGM2008 & -21.72 & 8.88 & 0.11 & 43 & 6.61 \\
JGEOID2008 & -20.20 & 8.44 & 0.18 & 97 & 5.99 \\
\hline
\end{tabular}

pressed with respect to the GRS80 ellipsoid. We should note that the geoid geometry is highly undulated in the area and that the differences at short wavelengths beyond the resolution of the GGMs are beyond the scope of the discussion here.

For EGM96, the existence of a systematic pattern is notable: a negative band between about $132^{\circ} \mathrm{E}$ and $138^{\circ} \mathrm{E}$ longitude with positive bands outside. This clearly indicates the systematic errors in EGM96 over a distance of several hundreds of kilometers. In contrast, no such feature is visible for GGM02C/EGM96. The tilt of the best-fit plane is reduced by about $43 \%$ from EGM96 to GGM02C/EGM96. Therefore, GGM02C/EGM96 is much more accurate at long wavelengths over Japan and suited for use as the reference GGM in the determination of a regional geoid model for Japan.

\section{Regional Gravimetric Geoid Modeling for Japan by Combining Terrestrial Gravity Data and Altimetric Gravity Model with GGM02C/EGM96}

An improved regional gravity field model for Japan is constructed by combining terrestrial gravity data and an altimetry-derived marine gravity model, KMS2002 with GGM02C/EGM96. The target area is set up at $20^{\circ}-50^{\circ} \mathrm{N}$ latitude and $120^{\circ}-150^{\circ} \mathrm{E}$ longitude. Since the quality of ship-borne gravity measurements at long wavelengths is rather low and KMS2002 reproduces the marine gravity field up to a wavelength of $800 \mathrm{~km}$ at maximum, we should solely use GGM02C/EGM96 for long-wavelength components. Intercomparisons between two GRACE-based combined GGMs, GGM02C and EIGEN-GL04C (Förste et al., 2007), show that the degree amplitudes of the differences begin to gradually increase above about degree 90 (the International Center for Global Earth Models, http://icgem.gfzpotsdam.de/ICGEM/ICGEM.html). Therefore, we will rely on GGM02C/EGM96 exclusively up to degree 90 and consider regional improvement with other data beyond that.

We used basically the same terrestrial (land and shipborne) gravity data as those for JGEOID2004 development. A bias and planar trend of the marine gravity data (after crossover adjustment) or KMS2002 with respect to GGM02C/EGM96 are adjusted beforehand. First, the marine gravity data and KMS2002 are combined for the sea into a $1 \times 1.5$ arc-minute grid of gravity anomaly by the semidiscrete wavelet analysis/reconstruction method with two-dimensional Halo wavelets: the marine gravity data are corrected with KMS2002, which is low-pass filtered at a cutoff wavelength of about $1.25^{\circ}$ and of which the erro- neous coastal areas having steep slopes in the bathymetry are removed. Next, a residual Faye anomaly grid is computed from the obtained regional gravity anomaly grid with reference to GGM02C/EGM96 and is high-pass filtered by a similar semidiscrete wavelet approach at a cutoff wavelength of $4^{\circ}$, which corresponds to degree 90 in spherical harmonics.

The residual Faye anomaly model obtained on a $1 \times 1.5$ arc-minute grid is used for regional geoid modeling by the same methodology as used by Kuroishi and Keller (2005). The generalized Stokes/Helmert integral is applied by using the one-dimensional fast Fourier transform in a remove-restore manner (Haagmans et al., 1993) with 100\% zero padding in the longitudinal direction. As for the zero gauges of the geoid, the geocentric gravitational constant and geoidal potential employed are taken from IERS Conventions 2003. We name the new gravimetric geoid model for Japan on a $1 \times 1.5$ minute grid JGEOID2008.

\section{Evaluation of Resulting Geoid Model for Japan, JGEOID2008}

JGEOID2008 is compared with the same GPS/leveling geoid undulations at 816 benchmarks that cover the four major islands of Japan, i.e., Honshu, Hokkaido, Shikoku, and Kyushu. The statistics of raw and postfit (planar fitting) differences between two gravimetric geoid models, JGEOID2004 and JGEOID2008, and the GPS/leveling geoid undulations are compiled in Table 2. For reference, the latest high-resolution global geopotential model, EGM2008 (Pavlis et al., 2008), is also included. Planar fitting is applied as a simple estimation of the longwavelength errors as the tilt of the plane and shortwavelength errors as indicating the deviation from the plane. JGEOID2008 exhibits major improvement over JGEOID2004. The planar trend is reduced by about half and the standard deviation (SD) of the postfit residuals is about 35\% smaller. Compared with EGM2008, JGEOID2008 shows a slightly larger planar trend, but significantly smaller SDs in both raw differences and postfit residuals. The result demonstrates that JGEOID2008 is superior to EGM2008 for Japan.

Figure 2 shows the geographical distribution of the postfit residuals. For comparison, the residual distribution for JGEOID2004 is also given. In the latter, a characteristic pattern is discernable at long wavelengths: JGEOID2004 is low, changing from high to low from west to east with respect to the GPS/leveling geoid undulations. On the contrary, no such systematic feature is observed in JGEOID2008. This highlights the realization of a significant diminution of long-wavelength errors with 
(a)

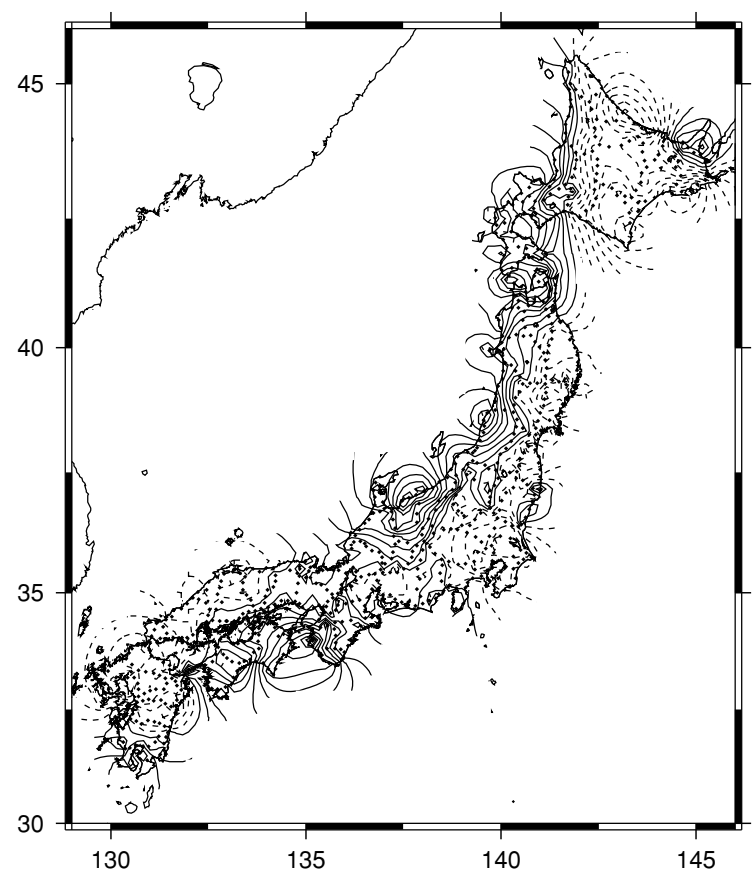

(b)

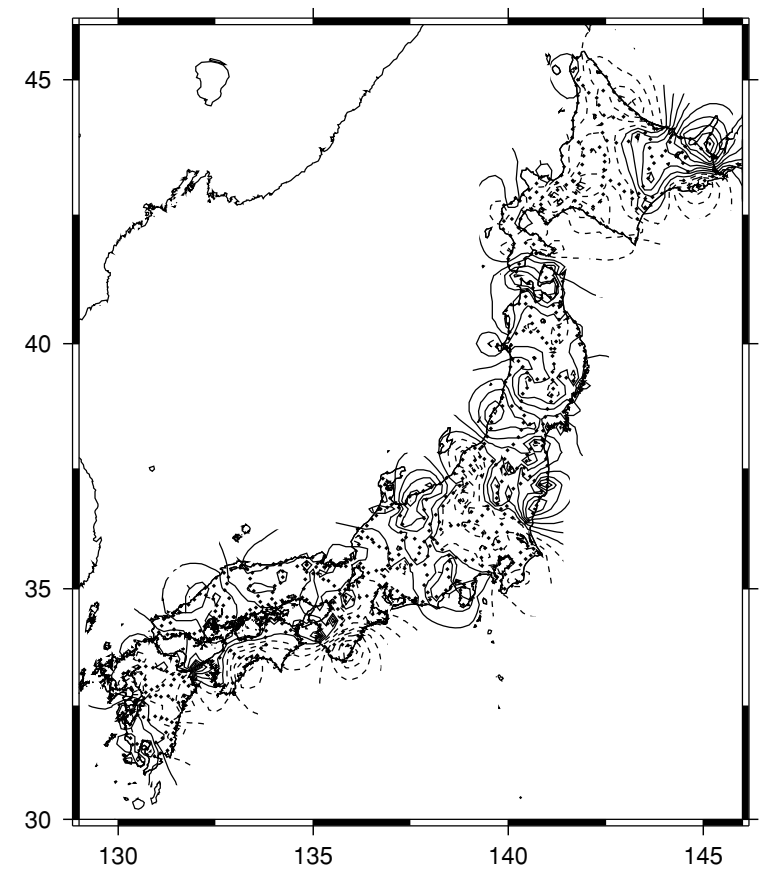

Fig. 2. Geoid differences between regional gravimetric geoid models and GPS/leveling geoid undulations over the main islands of Japan: (a) JGEOID2004 and (b) the new model, JGEOID2008. Best-fit planar trends are removed from both plots. Notations are the same as those in Fig. 1.

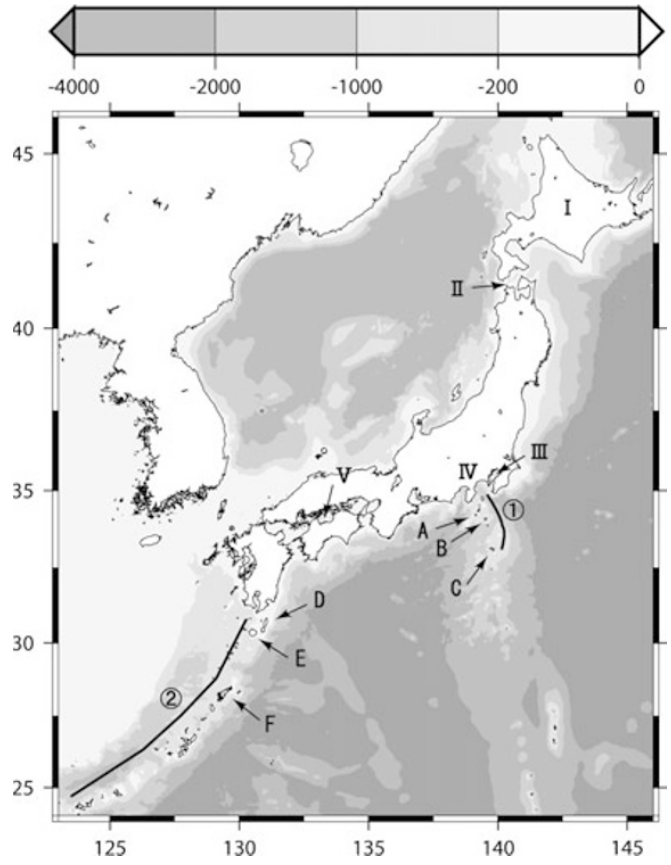

Fig. 3. Brief bathymetry around Japan and the locations for the geographic names cited in the text. Units of the scales above the image are meters. I: Hokkido Island, II: Tsugaru Strait, III: Tokyo Bay, IV: Kanto-Tokai areas, V: Seto Inland Sea, (1): Izu Island chain, (2): Nansei Islands; A: Kozushima, B: Miyakejima, C: Hachijojima, D: Tanegashima, E: Yakushima, and F: Amami-Oshima Islands.

\section{JGEOID2008.}

The Coastal Movement Data Center of Japan (secretariat at the Geographical Survey Institute, GSI) compiles and publishes tidal records and leveling survey results at more than 140 registered tidal stations and we can obtain orthometric heights of the local mean sea levels at most of these stations. Because orthometric heights at benchmarks on the four major islands are determined uniquely with reference to the mean sea level of Tokyo Bay, the heights of the local mean sea levels indicate the differences in mean SSDT between the local sea and Tokyo Bay. Readers refer to Fig. 3 for the locations corresponding to the geographic names cited in the text.

Figure 4(a) shows the orthometric heights of the local mean sea levels for the period 1990 to 1999 . The heights are calculated from the annual mean levels published, with the removal of the records that are suspected to have the contamination of vertical crustal movements associated with earthquakes and volcanic activities. No correction of the ocean surface temperature or atmospheric pressure was made for the mean levels and the calculation is performed only if annual mean levels are valid for at least three years.

Some areal features are clearly apparent in the figure.

- East to north Japan along the Pacific Ocean: about -5 to $-10 \mathrm{~cm}$

- Kanto to Tokai areas along the Pacific Ocean: nearly 0

- West Japan along the Pacific Ocean: about $+15 \mathrm{~cm}$

- Areas along the Seto Inland Sea: about $+10 \mathrm{~cm}$

- Hokkaido areas along the Japan Sea: about $+10 \mathrm{~cm}$

- Areas along the Japan Sea except Hokkaido: about $+20 \mathrm{~cm}$

- Areas along the East China Sea: about $+20 \mathrm{~cm}$

- Differences between north and south areas of Tsugaru Strait: about $+15 \mathrm{~cm}$

GPS/leveling geoid undulations are also measured by GSI on isolated islands and leveled heights are determined 
(a)

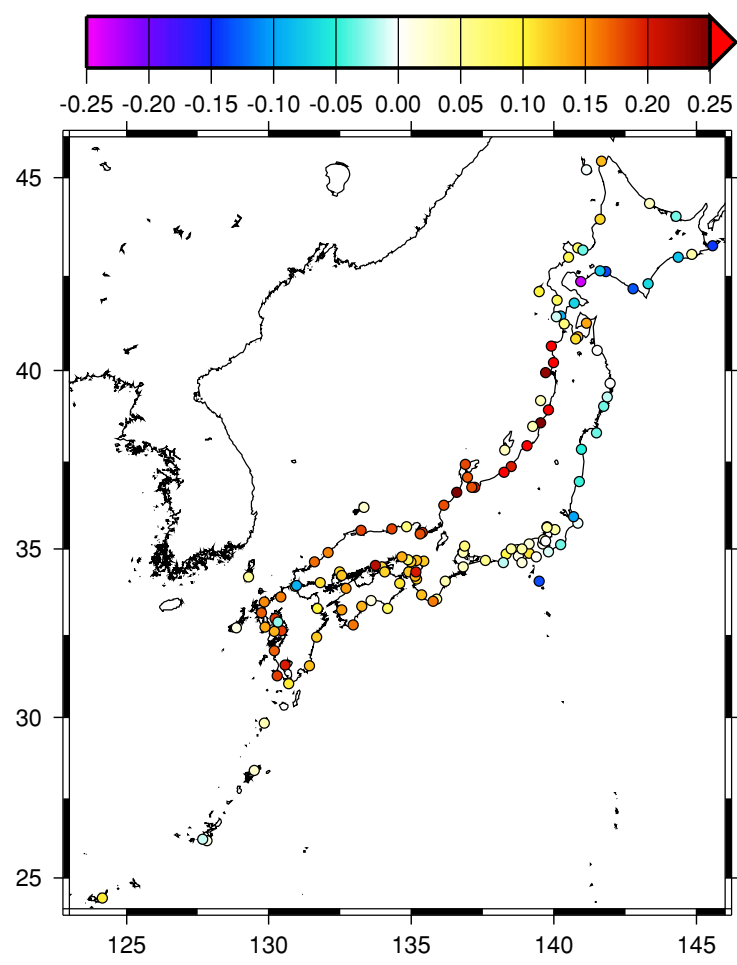

(b)

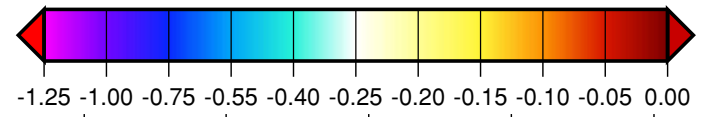

$-1.25-1.00-0.75-0.55-0.40-0.25-0.20-0.15-0.10-0.050 .00$

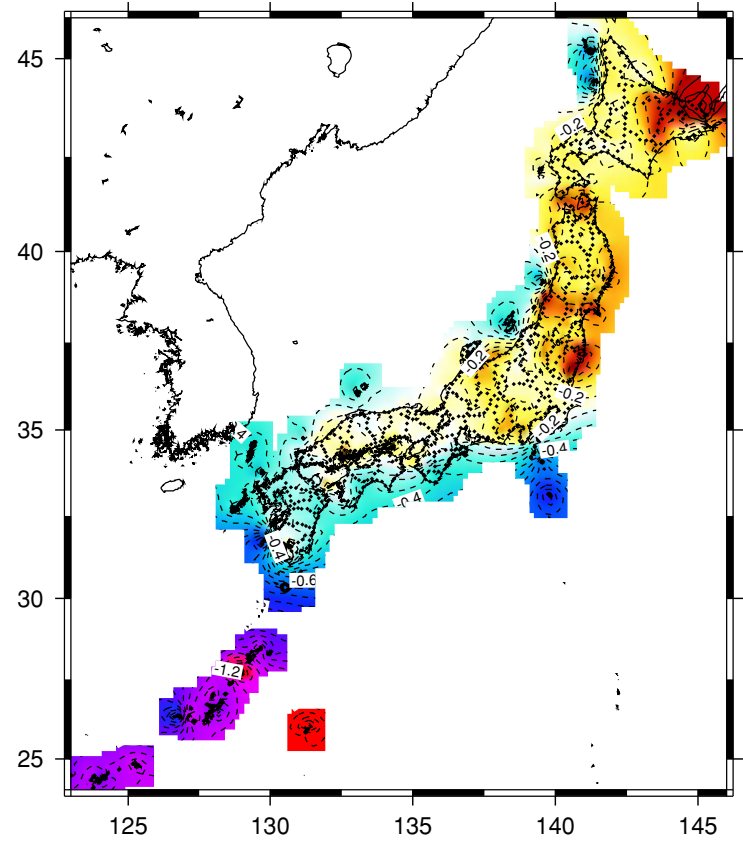

Fig. 4. (a) Orthometric heights of the local mean sea levels for the period 1990 to 1999 at tidal stations, and (b) geoid differences between JGEOID2008 and GP/leveling geoid undulations. Units of the scales above the images are meters in both plots, contour intervals are $5 \mathrm{~cm}$ and broken contours correspond to negative values in (b).

with reference to the local mean sea levels based on tidal records. If the mean SSDT of the local sea deviates from that of Tokyo Bay, the discrepancy propagates as a bias into the geoid differences between GPS/leveling geoid undulations and JGEOID2008 for such an island. We compare JGEOID2008 with the GPS/leveling geoid undulations at about 1300 benchmarks throughout the country (including those on the four major islands). The raw differences are given in Fig. 4(b). We note that the sign of the difference is opposite to that in Fig. 4(a), that is, a positive difference on an isolated island means for the zero-height level to be lower than the JGEOID2008 geoid.

Systematic discrepancies are observed in Fig. 4(b). We discuss here the differences on each island relative to the mean bias of about $-20 \mathrm{~cm}$ around the datum benchmark in Tokyo. Biases of about $-20 \mathrm{~cm}$ are distributed on islands in the Japan Sea. A gradual decline is found along the Izu Island chain: about 0 in the north down to about $-60 \mathrm{~cm}$ at Hachijojima Island. Significant negative differences are conspicuous in the Nansei Islands: about $-40 \mathrm{~cm}$ at Yakushima and Tanegashima Islands and about $-90 \mathrm{~cm}$ at Amami-Oshima Island and other southern islands.

Consistent biases found on the islands in the Japan Sea agree well with what we observed in orthometric heights of the local mean sea levels at the tidal stations along the Japan Sea (Fig. 4(a)). Geographical patterns of the systematic biases in the Nansei Islands and the Izu Island chain show good correlation with the mean axis of the Kuroshio Current. The Kuroshio Current flows northeastward west of the Nansei Islands, turns eastward between Amami-Oshima and Yakushima Islands and passes through the Izu Island chain. The dynamic height difference across the Kuroshio axis reaches an amplitude of $1 \mathrm{~m}$, which is in good agreement with the mean biases observed in Fig. 4(b). These correspondences indicated that the accuracy of JGEOID2008 over the surrounding seas is about a decimeter.

\section{Comparison of Sea Surface Dynamic Heights around Japan Obtained from JGEOID2008 and GPS/leveling and from Oceanographic Model}

To further discuss the differences between the local mean sea levels and the JGEOID2008 geoid, we compare them with a SSDT model estimated by an oceanographic approach. Averages of the differences are calculated on the respective isolated islands to facilitate the comparison and are shown in Fig. 5(a). The mean bias around the datum station (in the area of $35^{\circ}-36^{\circ} \mathrm{N}$ latitude and $139^{\circ}-140^{\circ} \mathrm{E}$ longitude) is counted as $-19.0 \mathrm{~cm}$ and removed from the averages in the plot.

The Japan Oceanographic Data Center operationally publishes the Regional Delayed Mode Data Base as part of the project of the North-East Asian Regional-Global Ocean Observing System (NEAR-GOOS; http://neargoos1.jodc.go.jp/index.html). Among many data sets are SSDTs and sea surface height anomalies in the Pacific Ocean analyzed every five days from Jason-1 satellite altimetry observation data. The difference between the two data sets is the mean SSDT for the period 1993 to 1996 , and the geographic distribution is shown in Fig. 5(b), in 
(a)

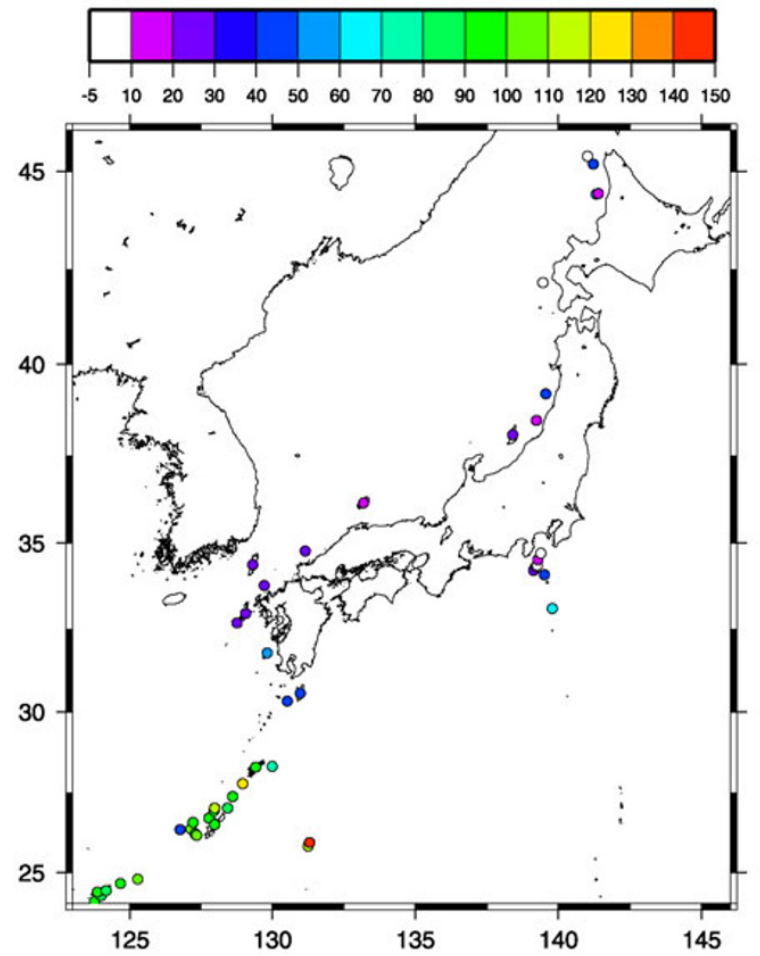

(b)

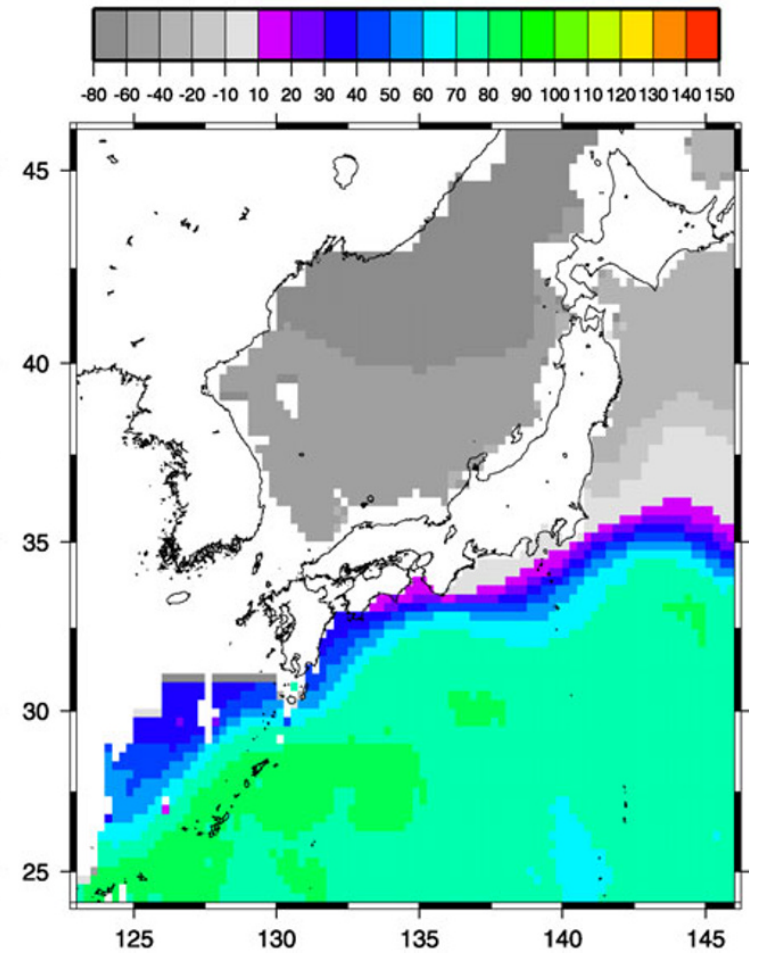

Fig. 5. (a) Mean biases of GPS/leveling geoid undulations above JGEOID2008 on respective isolated islands relative to that of $-19.0 \mathrm{~cm}$ around the datum benchmark, and (b) dynamic heights of the mean sea surface for the period 1993-1996 from NEAR-GOOS: a bias of -180 cm was removed. Units of the scales above the images are $\mathrm{cm}$.

which a bias of $-180 \mathrm{~cm}$ is removed to enable comparison. The mean SSDT is determined with reference to the depth of $1500 \mathrm{db}$ from a combination of altimetry and oceanographic observation data and a climatologic model by the method proposed by Kuragano and Shibata (1997). In their data process, ocean tides are removed using the model of Cartwright and Ray (1991) and atmospheric pressure effects are corrected under the inverse barometric assumption. The corrections applied are not exactly the same as those used in our handling of the tidal data and the mean SSDT model gives heights relative to the depth of $1500 \mathrm{db}$. Therefore, we should bear such differences in mind in the discussion.

Comparisons between Figs. 5(a) and 5(b) indicate good agreement with each other in SSDT relative to the mean sea level of Tokyo Bay, along the Nansei Islands and for the Izu Island chain: Kozushima $>+10 \mathrm{~cm}$, Miyakejima $>+30 \mathrm{~cm}$, Hachijojima $+60 \mathrm{~cm}$. In the Pacific Ocean, the agreement reaches the level of $10 \mathrm{~cm}$. On the other hand, no match is found in the Japan Sea. Kuragano and Shibata (1997) did not estimate SSDT for the Japan Sea, and the leveled heights of the mean sea level at tidal stations along the Japan Sea (Fig. 4(a)) favor the results in Fig. 5(a). Then we may infer that the mean SSDT model of NEAR-GOOS contains some bias in the Japan Sea.

Kuragano and Shibata (1997) estimated the accuracy of the mean SSDT model to be a few $\mathrm{cm}$. Even if we consider the differences in the correction between the two results, the good correspondence for the Pacific Ocean indicates that the precision of JGEOID2008 is within $10 \mathrm{~cm}$; therefore,
JGEOID2008 can be used as a reference level for ocean dynamics study.

\section{Concluding Remarks}

A highly improved gravimetric geoid model for Japan, JGEOID2008, was developed by combining a GRACEbased global geopotential model, GGM02C, concatenated with EGM96, surface (land and ship-borne) gravity measurements, and an altimetry-derived marine gravity model, KMS2002. In the combination, a semidiscrete twodimensional (2D) wavelet analysis/reconstruction method with Halo wavelets is employed, selecting the spatial wavelength signals of the highest quality out of the respective data sets. First, ship-borne gravity data are corrected with KMS2002, which is low-pass filtered by a semidiscrete 2D wavelet analysis/reconstruction method at a cutoff wavelength of about $1.25^{\circ}$ after the removal of erroneous coastal areas. Then, land gravity data and the corrected ship-borne gravity data are merged into a residual Faye anomaly model on a $1 \times 1.5$ minute grid with respect to GGM02C/EGM96. The residual Faye anomaly grid is high-pass filtered by the same semidiscrete wavelet approach but at a cutoff wavelength of $4^{\circ}$. Namely, the gravity field is determined from GGM02C/EGM96 at long wavelengths, the land gravity data at medium to short wavelengths, the ship-borne gravity data at short wavelengths, and KMS2002 at medium wavelengths at sea.

Intercomparison with GPS/leveling geoid undulations indicated substantial improvement of JGEOID2008 over the previous model, JGEOID2004: the planar trend was re- 
duced from $0.35 \mathrm{ppm}$ to $0.18 \mathrm{ppm}$, and the RMS of postfit residuals from $9.2 \mathrm{~cm}$ to $6.0 \mathrm{~cm}$ over the four main islands of Japan. It was also revealed that such systematic errors at long wavelengths as in JGEOID2004 have been effectively removed. Deviations of JGEOID2008 from the mean sea surface heights at tidal stations on isolated islands were comparable to the differences in the sea surface dynamic heights (SSDH) in the Japan Sea, the Nansei Islands and the Izu Island chain from that in Tokyo Bay. The deviations show good agreement with SSDH features estimated from oceanographic observation, revealing that the geoid model has an accuracy within $10 \mathrm{~cm}$.

Seas around Japan are very dynamic from an oceanographic viewpoint: for example, the Kuroshio Current, which is one of the strongest ocean currents and one of the largest sources of heat from the ocean to the atmosphere in the world, flows south of Japan. The combination of altimetry, oceanographic observation, and an accurate geoid model is effective for obtaining real pictures of ocean dynamics in geometrical and physical senses. Therefore, JGEOID2008 is strongly expected to serve as a reference in ocean dynamics studies.

Acknowledgments. The height data at tidal stations in Japan were obtained from the Coastal Movement Data Center of Japan at the Geographical Survey Institute and the sea surface height data were retrieved online from the Japan Oceanographic Data Center. The author expresses his sincere thanks for those activities. The author's thanks are also extended to Masaru Kaidzu for his encouragement. This work is supported by a Grant-in-Aid for Scientific Research (No. 17540402) from the Japan Society for the Promotion of Science. The images were created using GMT (Wessel and Smith, 1991).

\section{References}

Andersen, O. B., P. Knudsen, and R. Trimmer, Improved high resolution altimetric gravity field mapping (KMS2002 Global Marine Gravity Field), in A Window on the Future of Geodesy: Proceedings of the IUGG 23rd General Assembly, Sapporo, Japan, 2003, IAG Symp., edited by F. Sanso, 128, 326-331, Springer, New York, 2005.

Cartwright, D. E. and R. D. Ray, Energetics of global ocean tides from Geosat altimetry, J. Geophys. Res., 96, 16897-16912, 1991.

Ekman, M., Impacts on geodynamic phenomena on systems for height and gravity, Bull. Geod., 63, 281-296, 1989.

Förste, C., R. Schmidt, R. Stubenvoll, F. Flechtner, U. Meyer, R. König, H. Neumayer, R. Biancale, J.-M. Lemoine, S. Bruinsma, S. Loyer,
F. Barthelmes, and S. Esselborn, The GeoForschungsZentrum Potsdam/Groupe de Recherche de Geodesie Spatiale satellite-only and combined gravity field models: EIGEN-GL04S1 and EIGEN-GL04C, $J$. Geod., 82, doi:10.1007/s00190-007-0183-8, 2007.

Haagmans, R., E. de Min, and M. van Gelderen, Fast evaluation of convolution integrals on the sphere using 1D FFT and a comparison with existing methods of Stokes' integral, Manuscr. Geod., 18, 227-241, 1993.

Kuragano, T. and A. Shibata, Sea surface dynamic height of the Pacific Ocean derived from TOPEX/POSEIDON altimeter data: calculation method and accuracy, J. Oceanogr., 53, 585-599, 1997.

Kuroishi, Y., Precise gravimetric determination of geoid in the vicinity of Japan, Bull. Geogr. Surv. Inst., 41, 1-93, 1995.

Kuroishi, Y., An improved gravimetric geoid model for Japan, JGEOID98 and relationships to marine gravity data, J. Geod., 74, 745-755, 2001a.

Kuroishi, Y., A new geoid model for Japan, JGEOID2000, in Gravity, Geoid, and Geodynamics 2000, IAG Symp., edited by M. G. Sideris, 123, 329-333, Springer, 2001b.

Kuroishi, Y. and W. Keller, Wavelet approach to improvement of gravity field-geoid modeling for Japan, J. Geophys. Res., 110, B03402, doi:10.1029/2004JB003371, 2005.

Kuroishi, Y., H. Ando, and Y. Fukuda, A new hybrid geoid model for Japan, GSIGEO2000, J. Geod., 76, 428-436, doi:10.100/s00190-0020266-5, 2002.

Lemoine, F. G., D. E. Smith, L. Kunz, R. Smith, E. C. Pavlis, N. K. Pavlis, S. M. Klosko, D. S. Chinn, M. H. Torrence, R. G. Williamson, C. M. Cox, K. E. Rachlin, Y. M. Wang, S. C. Kenyon, R. Salman, R. Trimmer, R. H. Rapp, and R. S. Nerem, The development of the NASA GSFC and DMA joint geopotential model, in Gravity, Geoid and Marine Geodesy, IAG Symp., 117, edited by J. Segawa et al., 461-469, Springer, 1997.

McCarthy, D. D., IERS Conventions (2003), IERS Technical Note, 32, 2003.

Moritz, H., Geodetic Reference System 1980, Bull. Geod., 54, 395-405, 1980.

Pavlis, N. K., S. A. Holmes, S. C. Kenyon, and J. K. Factor, An Earth gravitational model to degree 2160: EGM2008, the 2008 General Assembly of the European Geosciences Union, Vienna, Austria, April 13-18, 2008

Smith, D. A. and D. G. Milbert, The GEOID96 high resolution geoid model for the United States, J. Geod., 73, 219-236, 1999.

Tapley, B. D., S. Bettadpur, J. C. Ries, P. F. Thompson, and M. M. Watkins, GRACE measurements of mass variability in the Earth system, Science, 305, 503-505, 2004.

Tapley, B., J. Ries, S. Bettadpur, D. Chambers, M. Cheng, F. Condi, B. Gunter, Z. Kang, P. Nagel, R. Pastor, T. Pekker, S. Poole, and F. Wang, GGM02C - an improved Earth gravity field model from GRACE, $J$. Geod., 79, doi:10.1007/s00190-005-0480-z, 2005.

Wahr, J., S. Swenson, V. Zlotnicki, and I. Velicogna, Time-variable gravity from GRACE: first results, Geophys. Res. Lett., 31, L11501, 2004.

Wessel, P. and W. H. F. Smith, Free software helps map and display data, EOS Trans., AGU, 72, 441, 445-446, 1991.

Y. Kuroishi (e-mail: yuki@gsi.go.jp) 